\title{
Effects of cabergoline in a pituitary adenoma secreting follicle-stimulating hormone
}

\author{
Graham Leese, Richard Jeffreys, Jiten Vora
}

\begin{abstract}
Summary
A patient with a pituitary adenoma secreting follicle-stimulating hormone with coexistent primary hyperaldosteronism is described. After his second transsphenoidal surgery, the patient developed a Staphylococcus aureus pituitary abscess. Symptoms improved after abscess drainage. Subsequent cabergoline therapy arrested the deterioration of symptoms, and decreased serum follicle-stimulating hormone concentrations. Cabergoline may be a useful treatment for aggressively growing non-prolactin-secreting pituitary adenomas.
\end{abstract}

Keywords: follicle-stimulating hormone, pituitary adenoma, cabergoline

Pituitary adenomas secreting follicle-stimulating hormone (FSH) are uncommon and often present at a late stage with aggressive tumour growth. Their management can be difficult. Despite most non-functioning pituitary tumours expressing membrane-bound dopamine receptors, ${ }^{1}$ the usefulness of dopamine agonists in non-prolactin-secreting pituitary adenomas remains uncertain. ${ }^{2}$ We present a patient with a rapidly growing pituitary adenoma secreting FSH which appeared to be sensitive to the dopamine agonist cabergoline.

\section{Case report}

A 54-year-old man had an FSH-secreting pituitary adenoma removed by transsphenoidal surgery. Baseline serum FSH concentration was $144 \mathrm{U} / 1$ and tissue immunohistochemistry was positive for FSH and negative for the other pituitary hormones, including prolactin. Postoperatively, the patient required hydrocortisone and testosterone. Two years after surgery and a course of radiotherapy, transsphenoidal resection was repeated because FSH concentrations remained elevated $(>40 \mathrm{U} / \mathrm{l})$ and computed tomography (CT) demonstrated persistent tumour within the enlarged sella. The serum FSH concentration was lower than previously, but remained elevated at $29.1 \mathrm{U} / 1$ and the patient required thyroxine replacement.

Four months after repeat surgery the patient was admitted with decreasing vision, worsening headaches and eye pressure. $\mathrm{He}$ was drowsy, had a low grade pyrexia (37.6C), and bitemporal hemianopia. Blood cultures were sterile and magnetic resonance imaging (MRI) demonstrated a large heterogenous pituitary mass with suprasellar extension into the third ventricle. A Staphylococcus aureus pituitary abscess was drained via subfrontal craniotomy. The patient was given intravenous and then oral flucloxacillin (2g qid) for four months. The headaches and vision improved and he was less lethargic.

Over the following six months the headaches and lethargy recurred, accompanied by decreasing visual acuity. The serum FSH concentration remained high $(26 \mathrm{U} / \mathrm{l})$, and there was no significant change in appearance on MRI. Octreotide was not tolerated and cabergoline $0.5 \mathrm{mg}$ twice weekly was started. Serum FSH concentration decreased to $2.5 \mathrm{U} / 1$ after three months of treatment, and was $2.1 \mathrm{U} / 1$ after eight months (figure). During this time prolactin concentrations decreased from 773 to $42 \mathrm{U} / \mathrm{l}$, and there was no further change in appearance of the pituitary on MRI. Headaches resolved and vision stabilised.

The patient had been treated for hypertension for over 20 years. Further investigations revealed a supine aldosterone:renin ratio of $2185 \mathrm{nmol} / \mathrm{h} / \mathrm{ng}$ and a standing ratio of 4950 $\mathrm{nmol} / \mathrm{h} / \mathrm{ng}$, suggestive of primary hyperaldosteronism. CT scan showed a $5-\mathrm{mm}$ nodule on the left adrenal. Blood pressure was maintained at $154 / 88 \mathrm{mmHg}$ on spironolactone and

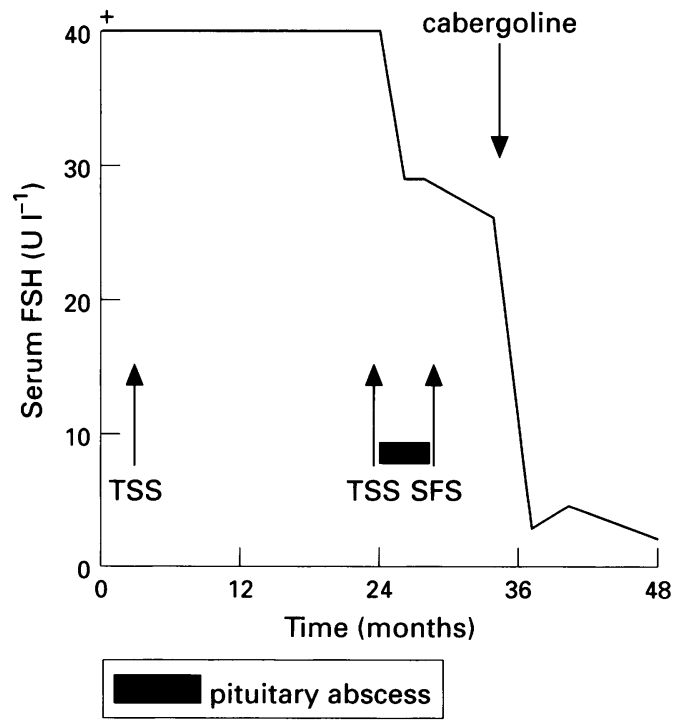

Figure Changes in serum FSH concentrations after transsphenoidal surgery (TSS), subfrontal surgery (SFS) and treatment with cabergoline 
captopril. The patient would not consider adrenal surgical intervention.

\section{Discussion}

The patient described had an aggressive FSHsecreting pituitary adenoma which appeared to be sensitive to the dopamine agonist cabergoline. The patient developed the unusual complication of a secondary Staphyloccocus aureus pituitary abscess, and also had coexisting primary hyperaldosteronism, a previously unreported association with a FSHsecreting pituitary adenoma. ${ }^{3}$

Dopamine agonists have been used successfully to shrink prolactin-secreting adenomas. ${ }^{3}$ Some non-functioning pituitary adenomas exhibit membrane-bound dopamine receptors which bind bromocriptine. ${ }^{1}$ When dopamine agonist drugs have been given, shrinkage of non-functioning pituitary adenomas has been demonstrated in some ${ }^{2,4}$ but not all studies. ${ }^{1,5}$ Van Schaardenburg et $a l^{2}$ showed that bromocriptine was able to arrest the growth of some non-functioning pituitary adenomas, even if tumour shrinkage did not occur. The other reported studies did not examine the rate of tumour growth before bromocriptine was started. It is therefore possible that in some of these tumours growth may have been arrested, even if not reversed by bromocriptine. In addition, tumour shrinkage appeared to occur predominantly in tumours which had undergone recent growth, ${ }^{2}$ which is likely to be in those with rapid and aggressive growth, as in our patient.

Bromocriptine has been shown to arrest the growth of ${ }^{6,7}$ and even cause regression in size

1 Bevan JS, Burke CW. Non-functioning pituitary adenomas do not regress during bromocriptine therapy but possess membrane bound dopamine receptors which

2 Van Schaardenburg D, Roelfsema F, Van Seters AP, Vielvoye GJ. Bromocriptine therapy for non-functioning pituitary adenoma. Clin Endocrinol 1989; 30: 475-84.

3 Liuzzi A, Chiodini PG, Dallabonzana D, Oppizzi G, Verde GG. Medical treatment of pituitary adenomas: effects on tumour growth. (Review article) 7 Endocrinol Invest 1985; 8: $273-81$.

4 Barrow DL, Tindall GT, Kovacs K, Thorner MO, Horvath E, Hoffman JC. Clinical and pathological effects of bromocriptine on prolactin secreting and other pituitary tumors. $\mathcal{F}$ Neurosurg 1984; 60: $1-7$.

5 Grossman A, Ross R, Charlesworth M, et al. The effect of Grossman A, Ross $R$, Charlesworth $M$, et al. The effect of
dopamine agonist therapy on large functionless pituitary tumours. Clin Endocrinol 1985; 22: 679-86.

6 Berezin M, Olchovsky D, Pines A, Tadmor R, Lunefeld B. Reduction of follicle stimulating hormone secretion in FSH-producing pituitary adenoma by bromocriptine. $\mathcal{f}$ Clin Endocrinol Metab 1984; 59: 1220-3.

\section{Learning points}

- some FSH-secreting tumours are responsive to dopamine agonists, eg, cabergoline

- this case demonstrates the co-existence of a pituitary adenoma and primary hyperaldosteronism

- pituitary abscesses are occasional but important sequelae to pituitary surgery

of a FSH-secreting pituitary adenoma. ${ }^{8} \mathrm{Ca}-$ bergoline has been used in an infertile woman with an apparent mixed prolactin and FSHsecreting macroadenoma; cabergoline resulted in a lowered serum concentration of each hormone, and in a successful pregnancy. ${ }^{9}$ Unfortunately, changes in adenoma size were not monitored. In our patient there was a dramatic decrease in serum FSH concentrations (figure), and the rapid decline in the patient's clinical condition was arrested after cabergoline was started. It was difficult to assess changes in size of the adenoma because of the presence of the cystic abscess within the pituitary, but there was at least no clear increase in size.

Thus, it appears that some FSH-secreting pituitary adenomas are sensitive to bromocriptine, ${ }^{6,7}$ cabergoline, (present case, ${ }^{9}$ ) and quinagolide. ${ }^{10}$ It is likely that these agents suppress tumour growth by acting via the dopamine receptors which can be expressed in these tumours. ${ }^{1}$ The more aggressively growing adenomas, such as in our patient, may be especially responsive to dopamine agonists. $^{2}$

7 Vance ML, Ridgway EC, Thorner MO. Follicle stimulating hormone and alpha subunit secreting pituitary tumor treated with bromocriptine. $\mathcal{F}$ Clin Endocrinol Metab 1985; 61: $580-4$

8 Abs R, Parizel PM, Beckers A. Acute effects of parlodelLAR and responses to long-term treatment with bromocriptine in a patient with a follicle stimulating hormonesecreting pituitary adenoma. f Endocrinol Invest 1991; 14: 135-8.

9 Paoletti AM, Depau GF, Mais V, Guerriero S, Ajossa S, Melis GB. Effectiveness of cabergoline in reducing folliclestimulating hormone and prolactin hypersecretion from pituitary macroadenoma in an infertile woman. Fertil Steril pituitary macroad

10 Kwekkeboom DJ, Lamberts SW. Long-term treatment with the dopamine agonist CV $205-502$ of patients with clinically non-functioning, gonadotroph, or $\alpha$-subuni secreting pituitary adenoma. Clin Endocrinol 1992; 36: $171-6$ 